\title{
Synthesis of CaxCu3-xTi4012 Perovskite Materials and house-hold LED light mediated degradation of Rhodamine Blue dye
}

\section{Priyankamoni Saikia}

Tezpur University

Hemanga Jyoti Sarmah

Tezpur University

Shahnaz Ahmed

Tezpur University

\section{Suman Lahkar}

Tezpur University

Jyoti Prakash Das

Tezpur University

Swapan Kumar Dolui ( $\nabla$ dolui@tezu.ernet.in )

Tezpur University

\section{Original Research Full Papers}

Keywords: Perovskite, Photocatalyst, Dye degradation, Calcium Copper Titanate, LED light

Posted Date: February 3rd, 2021

DOl: https://doi.org/10.21203/rs.3.rs-190338/v1

License: (c) (1) This work is licensed under a Creative Commons Attribution 4.0 International License.

Read Full License

Version of Record: A version of this preprint was published at Journal of Inorganic and Organometallic Polymers and Materials on February 22nd, 2021. See the published version at https://doi.org/10.1007/s10904-021-01929-y. 
Page 1 of 20

1 Synthesis of $\mathrm{Ca}_{\mathrm{x}} \mathrm{Cu}_{3-\mathrm{x}} \mathrm{Ti}_{4} \mathrm{O}_{12}$ Perovskite Materials and house-hold LED light

2 mediated degradation of Rhodamine Blue dye

3 Priyankamoni Saikia ${ }^{1}$, Hemanga Jyoti Sarmah ${ }^{2}$, Shahnaz Ahmed ${ }^{1}$, Suman Lahkar ${ }^{1}$,

$4 \quad$ Jyoti Prakash Das ${ }^{1}$ and Swapan Kumar Dolui ${ }^{1, *}$

$5 \quad{ }^{1}$ Department of Chemical Sciences, Tezpur University, Napaam, Tezpur, 784028, Assam,

$6 \quad$ India

$7 \quad 2$ Department of Physics, Tezpur University, Napaam, Tezpur, 784028, Assam, India

8 Corresponding author, Email ID: dolui@tezu.ernet.in, priyankam@tezu.ernet.in. 
Page $\mathbf{2}$ of $\mathbf{2 0}$

1 ABSTRACT: This report describes a comparative study of dye degradation under 20-watt

2 LED light using the perovskite photocatalyst Calcium Copper Titanate (CCTO) and its compositions $\left(\mathrm{Ca}_{x} \mathrm{Cu}_{3-\mathrm{x}} \mathrm{Ti}_{4} \mathrm{O}_{12}\right)(\mathrm{x}=1,1.5$ and 2$)$, synthesized by changing molar ratios of $\mathrm{Ca}^{2+}$

4 and $\mathrm{Cu}^{2+}$ ions. The $99.74 \%$ degradation of Rhodamine Blue $(\mathrm{RhB})$ with composition $(\mathrm{x}=1)$

5 within $6 \mathrm{~h}$ is reflected its better photocatalytic activity than the parent CCTO and other 6 compositions. The band gap energy of the materials $2.18 \mathrm{eV}$ (CCTO), $1.93 \mathrm{eV}(\mathrm{x}=1), 2.40 \mathrm{eV}$

$7 \quad(\mathrm{x}=1.5)$, and $2.55 \mathrm{eV}(\mathrm{x}=2)$ are analysed with $\mathrm{UV}-\mathrm{Vis}$ spectroscopy. The presences of $\mathrm{Ca}, \mathrm{Cu}$,

$8 \mathrm{Ti}$ and $\mathrm{O}$ in the synthesized photocatalysts are confirmed with Elemental X-ray Dispersive 9 (EDX) analysis. The cubic phases in the polyhedral shape of the materials are detected in Xray diffraction and Scanning Electron Microscopy (SEM). This report further observes the defect density concentrations of the materials with Photoluminescence Spectroscopy (PL) and provides the approximate explanation of their dye degradation performance as photocatalysts. The rate constants are found in a first order reaction trend; where the composition $(x=1)$ shows about $1.683 \times 10^{-2} \mathrm{~min}^{-1}$. The mechanistic understanding of the degradation process is also revisited and rationalized with different scavengers for the process.

Keywords: Perovskite, Photocatalyst, Dye degradation, Calcium Copper Titanate, LED light

\section{Introduction}

As we are shifting towards modernization, there is a rapid development of industrialization and urbanization which ultimately affects the ecosystem by discharging toxic elements and pollutants into the natural water cycle $[1,2]$. The treatment of wastewater is essential to maintain not only for a pollutant-free ecosystem of aquatic system, but also for a sustainable environment to the all living system [3-5]. As a part of waste management system, finding a sustainable approach to degrade the toxic pollutants is very urgent responsibility for both 
Page $\mathbf{3}$ of $\mathbf{2 0}$

1 small companies and big industries. Recently, the oxidation process by semiconductor-based

2 photocatalyst has emerged as one of the potential fields from sustainable chemistry. The

3 degradation process of the pollutants requires an active photocatalyst which can be excited by

4 the photons and generate electrons and holes which ultimately able to reduce the pollutants

5 [6-9]. Among the various photocatalyst; $\mathrm{TiO}_{2}, \mathrm{CdS}, \mathrm{ZnO}, \mathrm{WO}_{3}$ etc. are extensively used in

6 wastewater treatment [10-13]. Still there are some challenges for the catalysis process,

7 because of larger band gap of the aforementioned catalysts. $\mathrm{TiO}_{2}$ have a band gap of $3.2 \mathrm{eV}$

8 and the material need UV region to show photocatalytic activity. Since ordinary sunlight

9 contains only 5\% UV light, making $\mathrm{TiO}_{2}$ quite less effective in the degradation process under

10 sunlight condition [14]. The development of a photocatalyst having a narrow bandgap is one

of the crucial properties where visible light can be used in the degradation process. Moreover, the previously discussed materials have a high rate of recombination of electrons and holes, which limits their uses in the long run.

Among the various kinds of light active photocatalyst, the perovskite-based photocatalyst has a unique photophysical property due to its distinct advantages [15-19] Perovskite compounds such as $\mathrm{BaTiO}_{3}$ [20], $\mathrm{CaTiO}_{3}$ [21], $\mathrm{CoTiO}_{3}$ [22], $\mathrm{NiTiO}_{3}$ [23], $\mathrm{LaFeO}_{3}$ [24] are extensively used as a photocatalyst due to its favourable band edge properties.

In the family of perovskite photocatalyst, Calcium Copper Titanate (CCTO) has gained much attention as a cubic double perovskite which shows a good photocatalytic reaction against water pollutants and pharmaceutical wastes [25,26]. In crystallographic analysis, CCTO appears in ideal cubic structure of BBC lattice, bearing a space group of $\operatorname{Im} 3$, where $A$ site is shared by two ions that are $\mathrm{Ca}^{2+}$ and $\mathrm{Cu}^{2+}$ and the $B$ site is shared by $\mathrm{Ti}^{4+}$ ions [15]. Due to the difference in ionic radii tilting of the $\mathrm{TiO}_{6}$ octahedral plane maybe observed $[27,28]$. As $\mathrm{TiO}_{2}$ is a $\mathrm{UV}$ active photocatalyst and $\mathrm{CuO}$ is a visible light active photocatalyst, it was seen that an effective combination of these compounds makes CCTO a visible light 
1 active photocatalyst. In the past two decades, CCTO material has been widely investigated

2 for their various physical properties and applications [29,30]. The cationic substitution and its

concentration in CCTO material can largely manifest the photocatalytic activity [31]. CCTO material can be synthesized by two major methods one is a high-temperature solid-state method [26] another is a wet chemistry method [31]. The solid-state method has some disadvantages in maintaining the purity as the synthesised materials contain some impurities such as $\mathrm{CaTiO}_{3}$ and $\mathrm{CuO}$ etc. [32,33]. To resolve these disadvantages, the alternative developed methodologies are the wet chemistry method including polymerized complex [34,35], microwave dealing [36], sol-gel [33], co-precipitation method [37] and many more. Degradation of harmful dyes by CCTO have been reported by different groups $[17,38,39]$. Otitoju et. al. studied the degradation of Rhodamine Blue $(\mathrm{RhB})$ in the presence of $\mathrm{CaCu}_{3} \mathrm{Ti}_{4} \mathrm{O}_{12}$ modified polyethersulfone fibre membrane. [18]. Zhu and his co-workers studied the removal of ibuprofen in presence of CCTO catalyst under visible light irradiation [39]. Kushwaha's group studied the photocatalytic property of a composite of polyaniline and CCTO in the degradation of congo red and methyl orange under the illumination of a visible light source [17].

Though, degradation of harmful dyes by CCTO catalyst have been reported, but proper correlation of degradation with the defect density of the specimen have not addressed in the literature. Here, we synthesize of the CCTO and its compositions $\left(\mathrm{Ca}_{\mathrm{x}} \mathrm{Cu}_{3-\mathrm{x}} \mathrm{Ti}_{4} \mathrm{O}_{12}\right.$, where $\mathrm{x}=1,1.5,2$ ) by citrate precursor method with varying the molar ratios of $\mathrm{Ca}^{2+}$ and $\mathrm{Cu}^{2+}$ and the materials can be used for dye-degradation of Rhodamine Blue under user-friendly household 20-watt LED light. Surprisingly, the degradation of RhB is found better using composition of $\mathrm{x}=1$ than the parent $\mathrm{CCTO}$ and other compositions. The photoluminescence (PL) properties of all materials are studied and the defect density calculations are explained. The catalyst $\mathrm{Cax}_{\mathrm{x}} \mathrm{Cu}_{3-\mathrm{x}} \mathrm{Ti}_{4} \mathrm{O}_{12},(\mathrm{x}=1)$ have shown a promising result with $99.74 \%$ degradation, 
Page $\mathbf{5}$ of $\mathbf{2 0}$

within $6 \mathrm{~h}$. Additionally, the observed degradation efficiency of the synthesized materials and rate constants of the photocatalytic processes are studied with comparison of defect density concentrations calculated by PL studies.

\section{Experimental Section}

\subsection{Materials}

Calcium carbonate, $\mathrm{CaCO}_{3}\left(98.5 \%\right.$ Avantor), copper chloride dihydrate, $\mathrm{CuCl}_{2} .2 \mathrm{H}_{2} \mathrm{O}(99.0 \%$ Merck), anhydrous citric acid, $\mathrm{C}_{6} \mathrm{H}_{8} \mathrm{O}_{7}\left(99.0 \%\right.$ Merck), titanium dioxide, $\mathrm{TiO}_{2}(98.5 \%$ Merck) were purchased from commercial source and used a starting material, without any further purification.

\subsection{Methods}

Calcium Copper Titanate compositions were synthesized by conventional citrate precursor method reported by Turky et. al. [40]. $\mathrm{CaCO}_{3}, \mathrm{TiO}_{2}, \mathrm{CuCl}_{2} \cdot 2 \mathrm{H}_{2} \mathrm{O}$, and citric acid $\mathrm{C}_{6} \mathrm{H}_{8} \mathrm{O}_{7}$ was taken as a raw material. To prepare $\mathrm{CCTO}\left(\mathrm{CaCu}_{3} \mathrm{Ti}_{4} \mathrm{O}_{12}\right)$, the aqueous solution of $\mathrm{CaCO}_{3}$, $\mathrm{CuCl}_{2} .2 \mathrm{H}_{2} \mathrm{O}$, and $\mathrm{TiO}_{2}$ were mixed in molar ratio 1:3:4 respectively. The certain amount of Citric acid was also taken which acts as a complexing agent. The molar ratio of metal precursor to the citric acid is the amount of is 1:5. The obtained light-coloured solution was slowly heated at $80{ }^{\circ} \mathrm{C}$ to form a gel. Subsequently, the gel was calcinated at $1000{ }^{\circ} \mathrm{C}$ for 2 hours at a heating rate of $10{ }^{\circ} \mathrm{C} / \mathrm{min}$ in a muffle furnace to achieve the target material $\mathrm{CaCu}_{3} \mathrm{Ti}_{4} \mathrm{O}_{12}$ in perovskite structure. To prepare the CCTO derived material in various compositions, the above-mentioned compounds are now mixed in the different ratio of $\mathrm{x}: 3-$ $\mathrm{x}: 4$ where $\mathrm{x}=1,1.5$ and 2 . The synthesized materials are named as CCTO $(\mathrm{x}=1)$, CCTO $(\mathrm{x}=1.5)$ and $\mathrm{CCTO}(\mathrm{x}=2)$ respectively. 
Page 6 of 20

\section{2.3. Characterization}

2 To find the structural analysis, X-ray Diffraction (XRD) studies were carried using Rigaku

3 Miniflex X-ray diffractometer (Tokyo, Japan), equipped with $\mathrm{CuK}_{\alpha}$ radiation $(\lambda=0.15418$

$4 \mathrm{~nm}$, scanning rate $=0.05 \mathrm{~s}^{-1}$ ) at $30 \mathrm{kV}$ and $15 \mathrm{~mA}$; where data is acquired in the $2 \theta$ range of

$57^{\circ}$ to $80^{\circ}$. In addition, The FTIR spectra of the samples were recorded with a Nicolet Impact-

6410 IR spectrometer (USA) in the $\mathrm{KBr}$ medium at room temperature in the range of 4000-

$7400 \mathrm{~cm}^{-1}$, to have a proper understanding of IR active bonds present in the host system. In

8 optical studies, absorption and emission spectra were acquired using a Shimadzu UV-2550

9 and Hitachi F-2700 fluorescence spectrophotometer respectively. For morphological and elemental analysis, we employed Scanning electron Microscope (SEM) and elemental dispersive X-ray analysis technique (JEOL-JSM-6390LV). Additionally, the surface area and pore size of the material was evaluated by Brunaure Emmett-Teller (BET) using a BET analyser (Model 1000E, Quantachrome, USA).

\subsection{Photodegradation Procedure}

Light emitting diodes (LED) have many advantages like low consumption energy, longlasting life, and narrow-spectrum luminescence properties, etc. In this study, we have used a domestic visible LED light of $20 \mathrm{~W}$ (Philips LED lamp B22, 2000 lumen) which was placed at a distance of $8 \mathrm{~cm}$ just above the reaction vessel. The whole system was enclosed by a cardboard box of dimensions $44 \times 35 \times 36.5 \mathrm{~cm}^{3}$ (Length $\times$ Width $\times$ Height). The reaction was carried out at a temperature of $30 \pm 5{ }^{\circ} \mathrm{C}$; where, monitoring was carried out by an ordinary thermometer. Rhodamine Blue (RhB) stock solution was prepared in distilled water at a concentration of $100 \mathrm{ppm}$. Photodegradation of $\mathrm{RhB}$ dye solution was monitored by a Shimadzu UV-2550 spectrophotometer using a path length of $\sim 1 \mathrm{~cm}$. For the photocatalytic experiment, $50 \mathrm{mg}$ of catalyst was added to a $5 \mathrm{~mL}(100 \mathrm{ppm})$ dye stock solution which was 
1 diluted by $95 \mathrm{~mL} \mathrm{H}_{2} \mathrm{O}$ and $1 \mathrm{~mL} \mathrm{H}_{2} \mathrm{O}_{2}$ and stirred in dark for 12 hours to attain the

2 adsorption/desorption equilibrium. LED was switched on to start the experiment which was

3 continued for optimized hours. At a certain interval, $5 \mathrm{~mL}$ of the sample was taken out from

4 the reactor, centrifuged it and the dye content in the solution was analysed through absorption

5 spectroscopy.

\section{3. Results and discussion}

\section{$7 \quad$ 3.1. Powder X-ray diffraction}

8 As a part of structural analysis, Powder XRD technique was carried out for CCTO and its 9 compositions $(\mathrm{x}=1,1.5,2)$, the diffraction pattern was showed in the (ESI, Fig S1). The 10 diffraction peaks (220), (400), (422) planes was observed, which essentially corresponds to 11 the cubic phase of CCTO, in accordance to the JCPDS No. 75-2188 [40]. Some secondary 12 weak diffraction peaks were also observed which is due to the noise or impurities like $\mathrm{CuO}$ 13 and $\mathrm{TiO}_{2}$ [40]. Knowing the cubic phase of the material, the lattice parameter and the unit cell 14 volume for the specimen were calculated by using the following equations [41].

$$
d_{h k l}=\frac{a}{\sqrt{h 2+k 2+l 2}}
$$

$$
\mathrm{V}_{\text {cell }}=\mathrm{a}^{3}
$$

The degree of crystallinity can be estimated by the following relation [42].

$$
\text { Crystallinity }=\frac{\text { Area of } \text { crystallite peak }}{\text { Area of all peaks }}
$$

$$
D=\frac{0.9 \lambda}{\mathrm{B} \cos \theta}
$$


Page 8 of 20

where $D$ and $\lambda$ are defined as the crystallite size and the wavelength of $C u K_{\alpha}$

2 radiation. And, $2 \theta$ and $\mathrm{B}$ are defined as peak position and the full width half maximum

3 (FWHM) in radians respectively. The variations in structural parameters are depicted in the

4 Table 1.

5 Table 1. Structural parameters of produced Calcium Copper Titanate (CCTO) and its 6 compositions $(x=1,1.5,2)$.

\begin{tabular}{|c|c|c|c|}
\hline CCTO Compositions & $\begin{array}{c}\text { Volume of unit } \\
\text { cell }\left(\mathrm{cm}^{-3}\right)\end{array}$ & Crystallinity (\%) & $\begin{array}{c}\text { Crystallite size } \\
\text { (nm) }\end{array}$ \\
\hline CCTO & 0.433333 & 8.48 & 22.0 \\
\hline $\operatorname{CCTO}(x=1)$ & 0.396133 & 10.6 & 21.1 \\
\hline $\operatorname{CCTO}(x=1.5)$ & 0.394767 & 8.51 & 16.7 \\
\hline $\operatorname{CCTO}(x=2)$ & 0.40135 & 8.48 & 16.1 \\
\hline
\end{tabular}

7

\subsection{FT-IR Analysis}

9 For identifying the IR active bonding information, the materials were studied with the FT-IR 10 spectroscopy. The FT-IR spectra of CCTO and its compositions $(x=1,1.5,2)$ was showed in 11 Fig. S2 (ESI). The broad absorption peak at $\sim 3430 \mathrm{~cm}^{-1}$ can be attributed for O-H stretching 12 frequency [44]. Moreover, the absorption peak at $\sim 463 \mathrm{~cm}^{-1}$ is responsible due to the Ti-O-Ti 13 stretching frequency [45]. Furthermore, the $\mathrm{Cu}-\mathrm{O}$ and $\mathrm{Ca}-\mathrm{O}$ bending vibration can be 14 identified from the peak at $\sim 525 \mathrm{~cm}^{-1}$ at $606 \mathrm{~cm}^{-1}$ [45]. The evidence of an absorption band 15 located at 380-700 $\mathrm{cm}^{-1}$ can be considered due to the mixed vibrations of $\mathrm{TiO}_{6}$ and $\mathrm{CuO}_{4}$ [45]. 16 As the peak intensity of the $\mathrm{Cu}-\mathrm{O}\left(\sim 525 \mathrm{~cm}^{-1}\right)$ was gradually decreased from compositions

$17 \mathrm{x}=1$ to $\mathrm{x}=2$, this implied that the copper content was decreasing from compositions $\mathrm{x}=1$ to $18 \mathrm{x}=2$. 


\section{3.3. Morphological and elemental analysis}

2 The morphological characters in the CCTO derivatives were analysed using scanning 3 electron microscopy. The SEM images of the CCTO derivatives can be observed in Fig. S3

4 (ESI). As noticed from the image that the synthesised material was observed in polyhedral 5 shapes. These shapes maybe approximated to a cubic morphology. Further analysis 6 confirmed that particle have size in the range of $1 \mu \mathrm{m}$. The different calculated sizes of 7 particles were embedded in the same figure. It is well known that, polyhedral shape of 8 materials is a better candidate for the photocatalytic activity, so our synthesised material 9 possibly show a better activity as photocatalyst $[19,46]$. Further analysis on those images ensured us the presence of large microstructure matrix where small grains were ingrained in between the large grains.

The elemental information of the synthesized materials were analysed with Energy Dispersive X-Ray Spectrum (EDX) technique for CCTO specimen. EDX spectra of the materials were shown in the Fig. S4 (ESI). The presence of $\mathrm{Ca}, \mathrm{Cu}$, $\mathrm{Ti}$ and $\mathrm{O}$ in the host material was observed in the image. Different concentration of the elements was presented in the upper inset of the same figure.

\subsection{Absorption and emission Spectroscopy}

The optical properties, both absorption and emission responses were studied. For absorption studies, UV-Vis spectra were carried out in the range 200 to $800 \mathrm{~nm}$. The band gap energy of the specimen under study was estimated using the Tauc plot from derived absorption data. A straight-line can be drawn in order to estimate the band gap of the system, in accordance to the Tauc relation [40]

$$
(\alpha h v)^{m}=h v-E \mathrm{~g}
$$


where $\alpha$ is the optical absorption co-efficient, $h$ is the Planck's constant, $v$ is the Photon's frequency, $E g$ is the bandgap energy [40] and $m$ is a constant associated with a different type of transitions ( $m=1 / 2$ to indirect transitions and $m=2$ for direct transitions) [47]. In this case, we have considered the optical transitions as a result of allowed direct band to band transition. For CCTO, ССТO $(x=1)$, CCTO $(x=1.5)$, and CCTO $(x=2)$ (with different ratios of $\mathrm{Ca}$ and $\mathrm{Cu}$ ions the band gap energy was estimated to $2.18,1.93,2.40$, and $2.55 \mathrm{eV}$ respectively (ESI, Fig S5). Moreover, due to incorporations of $\mathrm{Cu}$ or $\mathrm{Ca}$ in the CCTO lattice caused the distortions in between $\mathrm{TiO}_{6}$ and $\mathrm{CaO}$ leading to the appearing of some intermediate levels in between the valence band and conduction band [40,48].

The photoluminescent (PL) emission Spectra of $\mathrm{Ca}_{x} \mathrm{Cu}_{3-\mathrm{x}} \mathrm{Ti}_{4} \mathrm{O}_{12}$ were studied and presented in the Fig S6 (ESI). The excitation peak for the luminescent spectra was fixed on the band gap of the respective specime. We observed an asymetric and broad spectra, implying prsence of surface or defect states in the host system [49]. A deconvulated spectra could be seen in the Fig. S6 (ESI). Upon deconvulation, we observed multiple peaks, for a band gap excitation. The first peak appearing near the band gap, maybe assigned for the near band edge emission. At the same time, other peaks could be associated with the defective origin, which usually appear in forbidden region. The defect density of the system was estimated by measuring the integral intensity (area under the curve) of the second peak, compared to the NBE peak. Theoretically, the intregal intensity for a defective peak qualititatvely represents better defect concentration in the system. We observed large integral intensity of defective peak with respect to NBE. for CCTO $(x=1)$ compared to the other samples, implying highest defect concetration. This maybe responsible for better photocatalytic activity of the specimen under study. 
Table 3: Comparison of defect density of different compositions of the photocatalyst.

2

3

4

5

6

7

8

9

\begin{tabular}{cc}
\hline Photocatalyst & $\begin{array}{c}\text { The integral intensity of the } \\
\text { defective peak }\end{array}$ \\
\hline CCTO & 1.2086 \\
CCTO $(\mathbf{x}=\mathbf{1})$ & 1.454 \\
CCTO $(\mathbf{x}=\mathbf{1 . 5})$ & 1.382 \\
CCTO $(\mathbf{x}=\mathbf{2})$ & 1.227 \\
\hline
\end{tabular}

\subsection{Photocatalytic activity}

To start the study the photo-catalysis activity of the prepared catalyst, we selected 20-Watt LED bulb as a light source, and Rhodamine dye (RhB) as a standard pollutant. Prior to the irradiation and catalyst addition, the UV-Vis spectroscopy of the prepared Rhodamine Blue $(\mathrm{RhB})$ stock solution was checked and observed a noticeable absorption peak at $552 \mathrm{~nm}$. The prepared catalyst were added to the solution and allowed for rigorous stirring for a period of $12 \mathrm{~h}$ to achieve adsorption-desorption equilibrium. Upon exposure to the LED light, we observed a clear drop in the absorption value of the spectra, merely signifying the degradation process (ESI, Fig S7). To be noted, in UV-Vis spectroscopy, the intensity of absorption depends on the amount of concentration; thus, declining trend of the absorption intensity confirms the degradation of the same. Degradation of RhB was achieved us using all the prepared catalyst, can be seen in the Fig. S7 (ESI). After illumination for 6 h, we noticed degradation efficiency to a value of $87 \%, 99.7 \%, 75 \%, 85 \%$ and for CCTO, CCTO (x=1), CCTO $(x=1.5)$ and CCTO $(x=2)$ respectively. The prepared catalyst CCTO $(x=1)$ exhibited a better performance as photo-catalyst. 
Page 12 of 20

1 The degradation percentage of Rhodamine blue was calculated by using the following 2 equation [50]:

3

$$
\text { Degradation rate }(r)=\frac{C_{o}-\mathrm{C}}{C_{o}} \times 100 \%
$$

4 Where, $C_{0}$ and $C$ are the concentration of Rhodamine Blue solution at $t=0$ (initial), and any

5 time $t$, respectively [50]. As the absoprtion in UV-Vis spectra depends on the concentration,

6 so the equation (6) maybe re-write in terms of absorbance, $A_{o}$ (initial) and $A$ (any time $t$ ) as:

$$
r=\frac{A_{o}-\mathrm{A}}{A_{o}} \times 100 \%
$$

8 Moreover, the kinetics of photocatalytic degradation of Rhodamine Blue was assumed to be

9 first order and reaction rate was determined by using the following Langmuir Hinselwood 10 kinetic equation

$$
\ln \left(C_{o} / C\right)=k t+\text { constant }
$$

$12 k$ is the first-order rate constant (unit is $\mathrm{min}^{-1}$ ), which can be calculated from the slope of the graph of $\ln \left(C_{\mathrm{o}} / C\right)$ versus irradiate time $t[38,50,51]$. The photocatalytic performance of the product of the different components of the ratio of $\mathrm{Ca}$ and $\mathrm{Cu}$ ions were compared in a typical photocatalyst experiment were analyzed (ESI, Fig S8). The degradation observed using CCTO was noticeable within first two hours, but it showed a saturation trend later. However, CCTO $(x=1)$ was found to show the most satisfactory result by degrading $99.74 \%$ in only $6 \mathrm{~h}$. While the other composite CCTO (x=1.5) and CCTO (x=2) showed only $78.85 \%$ and $99.95 \%$ degradation respectively. 
1 Table 2: Comparison of degradation efficiency of different compositions of the 2 photocatalyst

\begin{tabular}{cccc}
\hline Photocatalyst & $\begin{array}{c}\text { Degradation } \\
\text { percentage }\end{array}$ & $\begin{array}{c}\text { Irradiation time } \\
(\mathbf{m i n})\end{array}$ & $\begin{array}{c}\text { Degradation rate } \\
\text { constant }\left(\mathbf{m i n}^{-\mathbf{1}}\right)\end{array}$ \\
\hline CCTO & $99.6 \%$ & 1440 & $0.53 \times 10^{-2}$ \\
CCTO (x=1) & $99.74 \%$ & 360 & $1.683 \times 10^{-2}$ \\
CCTO (x=1.5) & $78.85 \%$ & 420 & $0.302 \times 10^{-2}$ \\
CCTO (x=2) & $99.95 \%$ & 440 & $0.444 \times 10^{-2}$
\end{tabular}

3 The rate constant for CCTO $(\mathrm{x}=1)\left(1.683 \times 10^{-2} \mathrm{~min}^{-1}\right)$ was found higher than that of the other

4 three compositions which are attributed due to the higher defect density than that of the other

5 compositions, which may be ensured from the PL studies. The defect density was increased

6 initially, with varying $\mathrm{x}$-value, before achieving saturation. When the material was changed

7 from CCTO to composition $\mathrm{x}=1$, the defect density was found improving, resulting an

8 enhancement of reaction rate. Analysing the same for compositions $x=1.5$ and 2 , the defect

9 density was observed declination gradually. The rate constant was dropped in similar trend abruptly (at $\mathrm{x}=1.5$ ), before getting saturated (Fig. S9 ESI). The comparison of the degradation efficiency and rate constants for different catalyst were shown in the Table 2. In our study, the best result was observed for $(\mathrm{x}=1)$ compositions, favouring a better degradation rate constant. The materials may be considered for waste water treatment.

\subsection{Surface Area Study.}

Brunaure Emmett-Teller (BET) was studied for the CCTO $(x=1)$ specimen. The pore volume and surface area obtained by the specimen under study were $0.024 \mathrm{cc} / \mathrm{g}$ and $3.009 \mathrm{~m} / \mathrm{g}^{2}$ respectively. The surface area of the material was high, which is a property of a good photocatalyst, and also large pore volume indicates the material as a good penetration of light 
Page 14 of 20

1 and contributing as an effective way of degrading the RhB dye [52]. The average pore radius

2 is about $22.162 \AA$. The BET isotherm indicated that the material was exhibited a type-III

3 isotherm (ESI, Fig S10).

4 4. Mechanistic Insight

5 To determine the active species in the degradation of Rhodamine Blue various scavenger test

6 was done. Isopropanol was used to identify $\mathrm{OH}^{\bullet}$ scavenger and p-benzoquinone for $\mathrm{O}_{2}{ }^{-}$

7 radical scavenger. The degradation of Rhodamine Blue in the presence of various scavengers

8 was highlighted (ESI, Fig S11). In addition to benzoquinone (BQ), the degradation process

9 was suppressed which indicates that the main active species in the degradation process is

10 superoxide anion $\left(\mathrm{O}_{2}{ }^{-}\right)$. When the visible light is irradiated on the surface of the CCTO

11 catalyst, electrons and holes are generated (ESI, Fig S12). The number of holes generated in

12 the valence band is the same as the number of electrons generated in the conduction band

13 [52]. The electrons from the conduction band react with absorbed oxygen to generate reactive

14 superoxide $\left(\mathrm{O}_{2}{ }^{-*}\right)$ radical which further reacts with water to produce hydroxyl radical $(\mathrm{OH} \cdot)$.

15 On the other hand, holes in the valence band react with a water molecule to generate $\mathrm{OH}$.

16 radical [50].

17 The main reactions are given below

$$
\mathrm{CCTO}+\mathrm{h} v \longrightarrow \mathrm{CCTO}\left(\mathrm{h}^{+}+\mathrm{e}^{-}\right)
$$

$$
\mathrm{CCTO}\left(\mathrm{h}^{+}\right)+\mathrm{H}_{2} \mathrm{O} \longrightarrow \mathrm{H}^{+}+\mathrm{OH}^{-}
$$

$$
\mathrm{CCTO}\left(\mathrm{e}^{-}\right)+\mathrm{O}_{2} \text { absorbed } \longrightarrow \mathrm{CCTO}+\mathrm{O}_{2}{ }^{-\cdot}
$$

$$
\mathrm{CCTO}\left(\mathrm{e}^{-}\right)+\mathrm{H}_{2} \mathrm{O}_{2} \longrightarrow \mathrm{CCTO}+\mathrm{OH}^{-}+\mathrm{OH}^{-}
$$

$$
\mathrm{O}_{2}{ }^{-\bullet}+\mathrm{H}_{2} \mathrm{O} \longrightarrow \mathrm{OH}^{\cdot}
$$




\section{5. Conclusion}

3 In summary, we have prepared a perovskite photocatalyst calcium copper titanate (CCTO)

4 and its compositions via the citrate precursor method. The prepared catalysts were observed

5 in polyhedral shape bearing a crystallographic cubic phase. The photocatalytic property of the

6 material was examined through the degradation of Rhodamine Blue dye under the

7 illumination of 20-Watt LED light. The efficiency of the degradation of the composition

8 CCTO $(x=1)$ was excellent, having a degradation efficiency of $99.74 \%$ within 6 hours. The

9 kinetic studies of the degradation process with the composition $x=1$ also showed the higher

10 rate constant of the reaction in comparison to other synthesized materials. The PL study of

11 the materials justified the higher defect concentration and followed by its photocatalytic

12 performance. This simple 20-watt LED light driven protocol for photodegradation of dye

13 could be very useful for medium scale pollutant cleaning or might possible in large scale too.

\section{$14 \quad$ Funding}

15 The author has received research support from Tezpur University for providing the 16 Institutional Fellowship.

\section{Corresponding Author}

18 Correspondence to Prof. Swapan Kumar Dolui.

\section{Conflict of Interest}

20 The authors declare that they have no conflicts of interest.

\section{Author Contributions}

22 The manuscript was written through the contributions of all authors. All authors have approved the final version of the manuscript. 
Page 16 of 20

\section{Acknowledgment}

2 The author would also like to thank the Sophisticated Analytical Instrumentation Centre

3 (SAIC), Tezpur University, India for providing analytical support.

$4 \quad$ Reference

5 [1] B. Lellis, C. Z. Fávaro-Polonio, J.A. Pamphile, J. C. Polonio, Biotechnology Research 6 and Innovation. 3, 275-290 (2019)

7 [2] D. A. Yaseen, M. Scholz,International journal of environmental science and 8 technology. 16, 1193-1226 (2019)

9 [3] S. Adhikari, A. V. Charanpahari, G. Madras, ACS omega. 10, 6926-6938 (2017)

10 [4] C. Kulsi, A. Ghosh, A. Mondal, K. Kargupta, S. Ganguly, D. Banerjee, Applied Surface 11 Science, 392, 540-548 (2017)

12 [5] C. Sarkar, C. Bora, S. K. Dolui, Industrial \& Engineering Chemistry Research, 53, 16148$1316155(2014)$

14 [6] A. Ghosh, M. Mitra, D. Banerjee, A. Mondal, RSC advances, 27, 22803-22811 (2016)

15 [7] X. Li, J. Xie, C. Jiang, J. Yu, P. Zhang, Frontiers of Environmental Science \& 16 Engineering, 12, $14(2018)$

17 [8] S. Dong, J. Feng, M. Fan, Y. Pi, L. Hu, X. Han, M. Liu, J. Sun, J. Sun, Rsc Advances, 19, $18 \quad 14610-14630(2015)$

19 [9] F. Opoku, K. K. Govender, C. G. C. E. van Sittert, P. P. Govender, Advanced Sustainable Systems, 1, $1700006(2017)$

21 [10] J. Yang, C. Chen, H. Ji, W. Ma, J. Zhao, The Journal of Physical Chemistry B, 109, $22 \quad 21900-21907(2005)$ 
Page $\mathbf{1 7}$ of 20

1 [11] B. Pan, Y. Xie, S. Zhang, L. Lv, W. Zhang, ACS applied materials \& interfaces, 4, $2 \quad 3938-3943(2012)$

3 [12] K.Intarasuwan, P. Amornpitoksuk, S. Suwanboon, P. Graidist, Separation and $4 \quad$ Purification Technology, 177, 304-312 (2017)

5 [13] X. Liu, H. Zhai, P. Wang, Q. Zhang, Z. Wang, Y. Liu, Y. Dai, B. Huang, X. Qin, X. 6 Zhang, Catalysis Science \& Technology, 9, 652-658 (2019)

7 [14] P. Magalhaes, L. Andrade, O. C. Nunes, A. Mendes, Reviews on Advanced Materials 8 Science, 51, (2017)

9 [15] J. H. Clark, M. S. Dyer, R. G. Palgrave, C. P. Ireland, J. R. Darwent, J. B. Claridge, M. 10 J. Rosseinsky, Journal of the American Chemical Society, 133, 1016-1032 (2011)

11 [16] A. Sen, K. K. Chattopadhyay, Journal of Materials Science: Materials in Electronics, 27, $12 \quad 10393-10398(2016)$

13 [17] H. S. Kushwaha, P. Thomas, R. Vaish, RSC advances, 5, 87241-87250 (2015)

14 [18] T. A. Otitoju, D. Jiang, Y. Ouyang, M. A. M. Elamin, S. Li, Journal of Industrial and Engineering Chemistry, 83, 145-152 (2020)

[19] P. Kanhere, Z. Chen, Molecules, 19, 19995-20022 (2014)

[20] K.Maeda, ACS applied materials \& interfaces, 6, 2167-2173 (2014)

[21] H. Zhang, G. Chen, Y. Li, Y. Teng, International journal of hydrogen energy, 35, 2713$2716(2010)$

[22] Y. Qu, W. Zhou, H. Fu, ChemCatChem, 6, 265-270 (2014)

[23] Y.Qu, W. Zhou, Z. Ren, S. Du, X. Meng, G. Tian, K. Pan, G.Wang, H. Fu, Journal of 
Page 18 of 20

1 [24] S. N. Tijare, M. V. Joshi, P. S. Padole, P. A. Mangrulkar, S. S. Rayalu, N. K.

2 Labhsetwar, International journal of hydrogen energy, 37, 10451-10456 (2012)

[25] M. Ahmadipour, M. Arjmand, S. N. Q. A. Abd Aziz, S. L. Chiam, Z. A. Ahmad, \& S. Y. Pung, Ceramics International, 45, 20697-20703 (2019)

[26] R. Hailili, Z. Q. Wang, X. Q. Gong, C. Wang, Applied Catalysis B: Environmental, 254, 86-97 (2019)

[27] S. Kawrani, M. Boulos, D. Cornu, M. Bechelany, ChemistryOpen, 8, 922-950 (2019)

[28] D. C.Sinclair, D. C., T. B. Adams,F. D. Morrison, A. R. West, Applied Physics Letters, 80, 2153-2155 (2002)

[29] K. Pal, A. Dey, P. P. Ray, N. E. Mordvinova, O. I. Lebedev, T. K. Mandal, M.M. Seikh A. Gayen, ChemistrySelect, 3, 1076-1087 (2018)

[30] P. R. Pansara, U. M. Meshiya, A. R. Makadiya, P. Y. Raval, K. B. Modi, P. M. G. Nambissan, Ceramics International, 45, 18599-18603 (2019)

[31] F. Moura, A. C. Cabral, L. S. R. Rocha, E. C. Aguiar, A. Z. Simões, E. Longo, Ceramics International, 42, 4837-4844 (2016)

[32] P. Thongbai, T. Yamwong, S. Maensiri, V. Amornkitbamrung, P. Chindaprasirt, Journal of the American Ceramic Society, 97, 1785-1790 (2014)

[33] S. Jin, H. Xia, Y. Zhang, J. Guo, J. Xu, Materials Letters, 61, 1404-1407 (2007)

[34] A. K. Rai, N. K. Singh, S. K. Lee, K. D. Mandal, D. Kumar, O. Parkash, Journal of alloys and compounds, 509, 8901-8906 (2011)

[35] S. Jesurani, S. Kanagesan, T. Kalaivani, K. Ashok, Journal of Materials Science: Materials in Electronics, 23, 692-696 (2012) 
Page 19 of 20

1 [36] J. Liu, Y. Sui, C. G. Duan, W. N. Mei, R. W. Smith, J. R. Hardy, Chemistry of

2 materials, 18, 3878-3882 (2006)

3

4

5

6

7

[37] D. Xu, K. He, R. Yu, X. Sun, Y. Yang, H. Xu, H. Yuan, J. Ma, Materials Chemistry and Physics, 153, 229-235 (2015)

[38] K. Pal, A. Mondal, R.Jana, P. P. Ray, A. Gayen, Applied Surface Science, 467, 543$553(2019)$

[39] Y. Zhu, T. Wang, W. Wang, S. Chen, E. Lichtfouse, C. Cheng C. Wang, Environmental Chemistry Letters, 17, 481-486 (2019)

[40] A. O. Turky, M. M. Rashad, Z. I. Zaki, I. A. Ibrahim, M. Bechelany, RSC Advances, 5, $18767-18772(2015)$

[41] J. Liu, R. W. Smith, W. N. Mei, Chemistry of Materials, 19, 6020-6024 (2007)

[42] A. Lopez-Rubio, B. M. Flanagan, E. P. Gilbert, M. J. Gidley, Biopolymers: Original Research on Biomolecules, 89, 761-768 (2008)

[43] A. K. Zak, W. A. Majid, M. E. Abrishami, \& R. Yousefi, Solid State Sciences, 13, 251$256(2011)$

[44] J. Yang, Z. Tang, H. Yin, Y. Liu, L. Wang, H. Tang, Y. Li, Polymers, 11, 766 (2019)

[45] S. Jesurani, S. Kanagesan, R. Velmurugan, T. Kalaivani, Journal of Materials Science: Materials in Electronics, 23, 668-674 (2012)

[46] K. Mogyorósi, K., N. Balázs, D. F. Srankó, E. Tombácz, I. Dékány, A. Oszkó, P.Sipos, A. Dombi, Applied Catalysis B: Environmental, 96, 577-585 (2010)

[47] S. Orrego, J. A. Cortés, R. A. C. Amoresi, A. Z. Simões, M. A. Ramírez, Ceramics International, 44, 10781-10789 (2018) 
Page $\mathbf{2 0}$ of $\mathbf{2 0}$

[48] P. Mishra, P. Kumar, Ceramics International, 41, 2727-2734 (2015)

2 [49] F. Moura, A. Z. Simoes, R. C. Deus, M. R. Silva, J. A. Varela, E. Longo, Ceramics 3 International, 39, 3499-3506 (2013)

4 [50] R. Sedghi., F. Heidari, RSC advances, 6, 49459-49468 (2016)

5 [51] M. Mitra, S. T. Ahamed, A. Ghosh, A. Mondal, K. Kargupta, S. Ganguly, D. Banerjee, $6 \quad$ ACS omega, 4, 1623-1635 (2019)

7 [52] M. Ahmadipour, M. Arjmand, Z. A. Ahmad, S. Y. Pung, Journal of Materials 8 Engineering and Performance, 1-9 (2020)

9 


\section{Supplementary Files}

This is a list of supplementary files associated with this preprint. Click to download.

- RevisedElectronicSupplementaryInformation.docx 